\title{
A novel genetic map of wheat: utility for mapping QTL for yield under different nitrogen treatments
}

Fa Cui ${ }^{1,2 \dagger}$, Xiaoli Fan ${ }^{1,3 \dagger}$, Chunhua Zhao ${ }^{1,2}$, Wei Zhang ${ }^{1,2}$, Mei Chen ${ }^{1,3}$, Jun $\mathrm{Ji}^{1,2}$ and Junming $\mathrm{Li}^{1,2^{*+}}$

\begin{abstract}
Background: Common wheat (Triticum aestivum L.) is one of the most important food crops worldwide. Wheat varieties that maintain yield (YD) under moderate or even intense nitrogen (N) deficiency can adapt to low input management systems. A detailed genetic map is necessary for both wheat molecular breeding and genomics research. In this study, an $\mathrm{F}_{6: 7}$ recombinant inbred line population comprising 188 lines was used to construct a novel genetic map and subsequently to detect quantitative trait loci (QTL) for YD and response to $N$ stress.
\end{abstract}

Results: A genetic map consisting of 591 loci distributed across 21 wheat chromosomes was constructed. The map spanned 3930.7 cM, with one marker per 6.7 cM on average. Genomic simple sequence repeat (g-SSR), expressed sequence tag-derived microsatellite (e-SSR), diversity arrays technology (DArT), sequence-tagged sites (STS), sequence-related amplified polymorphism (SRAP), and inter-simple sequence repeat (ISSR) molecular markers were included in the map. The linear relationships between loci found in the present map and in previously compiled physical maps were presented, which were generally in accordance. Information on the genetic and physical positions and allele sizes (when possible) of 17 DArT, 50 e-SSR, 44 SRAP, five ISSR, and two morphological markers is reported here for the first time. Seven segregation distortion regions (SDR) were identified on chromosomes 1B, 3BL, 4AL, 6AS, 6AL, 6BL, and 7B. A total of 22 and 12 QTLs for YD and yield difference between the value (YDDV) under HN and the value under LN were identified, respectively. Of these, $Q Y d-4 B-2$ and $Q Y d d V-4 B$, two major stable QTL, shared support interval with alleles from KN9204 increasing YD in LN and decreasing YDDV. We probe into the use of these QTLs in wheat breeding programs. Moreover, factors affecting the SDR and total map length are discussed in depth.

Conclusions: This novel map may facilitate the use of novel markers in wheat molecular breeding programs and genomics research. Moreover, QTLs for YD and YDDV provide useful markers for wheat molecular breeding programs designed to increase yield potential under $\mathrm{N}$ stress.

Keywords: Genetic map, Molecular marker, Quantitative trait loci, Wheat, Yield

\section{Background}

Common wheat (Triticum aestivum L.) has an allohexaploid genome (AABBDD, $2 n=6 x=42$ ) with seven groups of homoeologous chromosomes, which complicates genetic and functional analyses in this species. The draft genome sequences of the wheat A-genome progenitor

\footnotetext{
* Correspondence: ljm@sjziam.ac.cn

${ }^{\dagger}$ Equal contributors

${ }^{1}$ Center for Agricultural Resources Research, Institute of Genetics and Developmental Biology, Chinese Academy of Sciences, Shijiazhuang 050022, China

${ }^{2}$ State Key Laboratory of Plant Cell and Chromosome Engineering, Chinese Academy of Sciences, Beijing 100101, China

Full list of author information is available at the end of the article
}

Triticum urartu and the D-genome progenitor Aegilops tauschii were recently released; these sequences can provide new insights into the $\mathrm{A}$ and $\mathrm{D}$ genomes and directly support map-based gene cloning [1,2]. However, accurate and detailed genetic maps are required for the molecular breeding of wheat and genomics research in this species.

A dense linkage map covering all 21 chromosomes is necessary for whole genome mapping in wheat; to produce such a map, various marker types should be combined. Microsatellites or simple sequence repeats (SSRs) are easy to use, exhibit a high degree of polymorphism, and frequently show co-dominant inheritance. Röder 
et al. [3] compiled the first g-SSR-based map of wheat, which included 279 loci. e-SSRs are derived from expressed genes, and their sequence information can be used to glean information on the function of the associated genes [4-6]. Gao et al. [7] reported the first wheat genetic map with 101 e-SSR loci. Inter-simple sequence repeat (ISSR) markers are reliable and share some of the advantages of microsatellites. Moreover, ISSRs have characteristics that are not species-specific $[8,9]$. However, to date, few ISSRs have been documented in wheat genetic maps [5].

Sequence-related amplified polymorphisms (SRAPs), which are based on open reading frames (ORFs) developed from genome sequence data of Arabidopsis, represent a novel PCR-based molecular marker technique [10]. SRAP targets functional genes and therefore can be efficiently used for purposes including gene tagging, marker-assisted selection (MAS), and genome-wide association studies [10,11]. Moreover, SRAPs have numerous other advantages such as multilocus and multiallelic features, cost-effectiveness, and a lack of crop specificity. To date, few SRAP markers have been identified in wheat $[5,11]$.

Diversity arrays technology (DArT) was developed as a hybridization-based alternative that captures the value of the parallel nature of the microarray platform [12]. This technique can generate hundreds of high-quality genomic dominant markers with high efficiency (http://www. diversityarrays.com/). Several wheat genetic maps that include DArT markers have been produced [12-19].

Wheat varieties that maintain yield under moderate or even intense nitrogen $(\mathrm{N})$ deficiency can adapt to low input management systems. To breed such varieties, genetic variation for adaption traits to $\mathrm{N}$ deficiency is required. To date, limited quantitative trait loci (QTL) for both yield and its response to $\mathrm{N}$ deficiency in wheat under field conditions have been documented [20-22]. Detection of favorable alleles for yield that decrease difference between the value under high $\mathrm{N}(\mathrm{HN})$ and the value under lower $\mathrm{N}(\mathrm{LN})$ are of value in wheat breeding programs designed to increase $\mathrm{N}$-deficiency tolerance.

In the present study, we develop a genetic map using a recombinant inbred line (RIL) population and compare this map with previously constructed physical maps. Genetic and physical positional information for more than 100 loci derived from SRAP, ISSR, e-SSR, and DArT markers are presented for the first time in this paper. Chromosomal regions harboring QTL for yield and yield sensitivity to $\mathrm{N}$ stress are specified, and we also inquire into their use in wheat molecular breeding programs. In addition, factors affecting the occurrence of segregation distortion regions (SDRs) and the total map length are discussed in depth.

\section{Methods}

\section{Plant material and molecular markers}

An $\mathrm{F}_{6: 7}$ RIL population (denoted $\mathrm{KJ}$ ) derived from a cross between Kenong9204 (KN9204) and Jing411 (J411) was used in this study. KN9204 was released in 2002 by the Center for Agricultural Resources Research, Institute of Genetics and Developmental Biology, Chinese Academy of Sciences, Hebei, China. As one of the representative cultivars in the North China Plain, it has higher yield potential and nitrogen use efficiency (NUE) than most other commercial cultivars [23,24]. The original RIL population contained 427 RILs. In this study, 188 randomly sampled lines from the 427 KJ-RILs were used for genetic linkage analysis and QTL detection.

The g-SSR, e-SSR, ISSR, STS, and SRAP molecular markers were used to genotype the parents and their derived lines. Information on g-SSR markers, including those with BARC, CFA, CFD, CFT, GWM, GDM, GPW, and WMC codes, and information on PCR-based STS markers with a MAG code was obtained from the GrainGenes website (http://wheat.pw.usda.gov). Relevant information on e-SSR markers with a CFE, KSUM, or CNL prefix is publicly available (http://wheat.pw.usda.gov/ITMI/E-SSR/). Information on e-SSR markers with the prefixes CWEM, EDM, CWM, CINAU, SWES, CAU, and BE/BF was published in reference articles by Peng and Lapitan [25], Mullan et al. [26], Gao et al. [7], Zhuang et al. [27], Li et al. [5,28], Yang et al. [29], and Lu et al. [30], respectively. ISSR markers were developed by the University of British Columbia Biotechnology Laboratory (UBCBL) [9]. Relevant information on SRAPs was obtained from an article written by Li and Quiros [10]. Polymorphic primer sequences for ISSRs and SRAPs are listed in (Additional file 1: Table S1). Information on DArT markers is publicly available (http://www.triticarte.com.au/). Information on the functional markers $A \times 2^{*}, G l u-b 3 h$, PPO33, and STSO1 was published in reference articles by Liu et al. [31]. The three functional markers FM1, In10, and FM2 were developed by our research group and will be described in a forthcoming paper.

\section{Analysis of molecular/morphological markers and map construction}

We used the touchdown PCR protocol described by Hao et al. [32] using a TaKaRa PCR thermal cycler (TaKaRa, Dalian, China). The amplification products were analyzed by polyacrylamide gel electrophoresis (PAGE), as described by Singh and Shepherd [33]. Seedling leaves were used to prepare DNA for DArT analysis following the recommended DNA extraction method (http://www.triticarte.com.au/content/DNA-preparation. html). All 427 RILs and their parents were assayed using the 'Wheat PstI (TaqI) 2.3 D' DArT array (the medium density array) (http://www.triticarte.com.au/). However, 
low DNA concentrations resulted in a limited number of polymorphic DArT markers.

The morphological markers coleocolor for the coleoptile color (green for KN9204, purple for J411) and leaftype for the flag leaf type (curling for KN9204, flat for J411) segregated as Mendelian factors (qualitative character inheritance) in the RIL population; these markers were phenotyped and assigned 'A' or 'B' scores for the linkage analysis.

The linkage groups were constructed using MAPMAKER 3.0 [34]. First, the 'MAKE CHROMOSOME' command was used to form 21 groups. Subsequently, the 'ANCHOR' command was used to assign SSR markers to their corresponding chromosomes using information from the publicly available genetic maps provided in GrainGenes 2.0 (http://wheat.pw.usda.gov/GG2/index.shtml). Anchor loci were chosen according to the following criteria: an absence of segregation distortion, minimal missing data, and optimal spacing along the chromosomes. The remaining markers were assigned to chromosomes using the 'ANSIGN' command at a log-of-odds (LOD) score of 2.5 and a distance of less than $45 \mathrm{cM}$. The 'ORDER' command determined the framework of each group. The 'TRY' command placed the remaining loci into the best fits (i.e., into the most likely intervals) of the corresponding groups at a LOD score of 2.0 and a distance of less than $50 \mathrm{cM}$. The 'MAP' command produced the linkage map. Lastly, the 'RIPPLE' command tested the robustness of each linkage map. The clusters that were identified as belonging to the same group were not linked if the distance between them was greater than $50 \mathrm{cM}$. The distances (in centiMorgans) were calculated using the Kosambi mapping function [35]. The map was drawn with MapChart 2.2 [36] (http://www.biometris.nl/ uk/Software/MapChart/).

The observed segregation ratios were tested by chisquare analysis (1:1). A SDR was defined by at least three adjacent marker loci exhibiting a significant segregation distortion $(\mathrm{P}<0.05)$. To validate the marker order of our genetic map, we compared the linear relationships between markers common to the new genetic map and to previously compiled physical maps [16,37-42]. For markers with discrepancies in chromosomal assignments and orders, we carefully checked the marker scores and re-estimated the positions of their corresponding loci.

\section{Field arrangement, trait evaluation, and QTL detection}

The RILs and their parents were evaluated in Shijiazhuang in 2011-2012 (E1: 37 $53^{\prime} \mathrm{N}, 114^{\circ} 41^{\prime} \mathrm{E}$, altitude $54 \mathrm{~m}$ ) and in 2012-2013 (E2), in Beijing in 2012-2013 (E3: 4006 ${ }^{\prime} \mathrm{N}$, $116^{\circ} 24^{\prime} \mathrm{E}$, altitude $41 \mathrm{~m}$ ) and in Xinxiang in 2012-2013 (E4: $35^{\circ} 27^{\prime} \mathrm{N}, 113^{\circ} 48^{\prime} \mathrm{E}$, altitude $95 \mathrm{~m}$ ). Two nitrogen treatments were applied in each trial ( $\mathrm{LN}$ and $\mathrm{HN}$ ) for a total of eight environments (year $\times$ location $\times$ treatment) designated E1-LN, E1-HN, E2-LN, E2-HN, E3-LN, E3$\mathrm{HN}, \mathrm{E} 4-\mathrm{LN}$ and E4-HN. The soil nitrate-nitrogen (N) contents within the $0-20 \mathrm{~cm}$ layer in each environment are shown in (Additional file 1: Table S2). In each HN plot, $300 \mathrm{~kg} \mathrm{ha}^{-1}$ of diamine phosphate and $150 \mathrm{~kg} \mathrm{ha}^{-1}$ of urea were applied before sowing, and $150 \mathrm{~kg} \mathrm{ha}^{-1}$ of urea were applied at the elongation stage every year. In the $\mathrm{LN}$ plots, no $\mathrm{N}$ fertilizer (N-deficient) was applied throughout the growing period. A randomized block design with two replications was used in each of the eight environments, and 40 seeds were hand-planted in each row of a two-row plot with 2 -m long rows spaced $0.25 \mathrm{~m}$ apart. All of the recommended agronomic practices were followed in each of the trials except for the fertilization treatment described above.

For each plot, five representative plants in the center of each row were selected at physiological maturity to measure the yield per plant (YD). The difference between the value under $\mathrm{HN}$ and the value under $\mathrm{LN}$ in each trial was calculated as follows: $Y D D V=Y D_{(H N)}-Y D_{(L N)}$, where YDDV is the difference of the yield per plant for each line in each trial between the values under $\mathrm{HN}$ and that under $\mathrm{LN}, Y D_{(H N)}$ and $Y D\left(_{L N)}\right.$ represent YD under $\mathrm{HN}$ and $\mathrm{LN}$, respectively. The broad-sense heritability $\left(h_{\mathrm{B}}^{2}\right)$ of the corresponding traits was calculated using the formula $h_{\mathrm{B}}^{2}=V_{G} /$ $V_{P}$ in QGAStation 2.0 (http://ibi.zju.edu.cn/software/qga/ v2.0/index_c.htm), where $V_{G}$ and $V_{P}$ are the genetic variance and phenotypic variance, respectively. The data from each environment were assembled individually according to the QTLData format of QGAStation 2.0. The first two columns represent the block (two replications) and genotype (the 188 lines), and the following columns represent YD and YDDV in each environment. The 'environment effect' 'and block effect' were attributed a value of 'NO' and 'YES' in 'Ge Var' analysis, respectively. To estimate the genetic by $\mathrm{N}$ treatment interaction variance $\left(V_{G \times T}\right)$ for YD, the data from each trial (LN and HN) were assembled individually according to the QTLData format of QGAStation 2.0. The first three columns represent the treatment ( $\mathrm{LN}$ and $\mathrm{HN}$ ), block (two replications), and genotype (the 188 lines), and the following column was YD. Both the 'environment effect' 'and block effect' were attributed a value of 'YES' in 'Ge Var' analysis.

The inclusive composite interval mapping performed with IciMapping 3.3 (http://www.isbreeding.net/) was used to detect putative additive QTLs. For YD, the phenotypic values of the 188 RILs in E1-LN, E1-HN, E2-LN, E2-HN, E3-LN, E3-HN, E4-LN, and E4-HN were used for individual environment QTL mapping. Concerning YDDV, the phenotypic values of the 188 RILs in E1, E2, E3, and E4 were used for individual environment QTL mapping. The walking speed chosen for all QTLs was $1.0 \mathrm{cM}$ and the $P$-value inclusion threshold was 0.001 . The threshold LOD scores were 
calculated using 1,000 permutations with a type 1 error of 0.05 .

\section{Results \\ Molecular and morphological marker screening in the parental lines and in the $188 \mathrm{KJ}-\mathrm{RILs}$}

Polymorphisms between the KN9204 and J411 lines were found in $48.7 \%, 27.5 \%, 34.7 \%, 3.0 \%$, and $3.7 \%$ of the primer pairs for the g-SSR, e-SSR, STS, ISSR, and SRAP markers, respectively. Using information from a survey of a highdensity microsatellite consensus map [43], we selected 515 evenly distributed polymorphic g-SSR markers on each chromosome to produce the framework of the genetic map. For g-SSR markers, 174 primer pairs for 180 loci were polymorphic, including 63 WMC, 38 GWM, 35 BARC, 14 CFD, 11 GPW, seven GDM, four CFA, and one CFT code markers and 64, 38, 38, 14, 12, eight, four, and one loci, respectively. The primer pairs for $\mathrm{Xgdm} 88$, $X w m c 402$, and Xgpw5215 each amplified two polymorphic loci, and the primer pair for Xbarc1138 amplified four polymorphic loci. Forty-two polymorphic primer pairs for 50 loci of e-SSR markers were tested, including 14 CFE, seven KSUM, six CNL, six CAU, three SWES, two CINAU, one EDM, one CWEM, one BE, and one BF code markers and 14,11, seven, seven, four, two, two, one, one, and one loci, respectively. The primer pairs for Xcnl62, Xcau14, Xswes96, and Xedm149 each amplified two polymorphic loci, and the primer pair for $X k s u m 174$ amplified five polymorphic loci. Fifteen STS primers with a MAG prefix for 17 loci were polymorphic, and only the primers for Xmag2931 amplified two polymorphic loci. Polymorphism was also observed in 27 SRAP primer pairs for 46 loci and in three ISSR primers for six loci; each primer produced one to three polymorphic loci and an average of 1.73 and 2.0 loci. The seven primer pairs for the functional markers $A x 2^{*}, F M 1, G l u-b 3 h$, In10, PPO33, STS01, and FM2 each produced their corresponding unique diagnostic fragments. The DArT analysis detected only 298 polymorphic DArT markers. The two morphological markers coleocolor and leaftype produced the qualitative inheritance of the relevant characteristic in the RIL population with a 1:1 segregation ratio, resulting in two morphological loci.

\section{The novel genetic linkage map}

Three PCR-derived polymorphic loci amplified by the primer pairs for Xiss807, Xme7em10, and Xme12em20 and 11 loci detected by DArT analysis could not be assigned to chromosomes; these 14 polymorphic loci were therefore excluded. Moreover, 31 gaps that had a linkage distance greater than $40 \mathrm{cM}$ but less than $50 \mathrm{cM}$ were excluded from the count of the total map length. The genetic map based on the 188 KJ-RIL lines contained 591 loci on 21 wheat chromosomes and spanned
$3930.7 \mathrm{cM}$, with an average density of one marker per $6.7 \mathrm{cM}$ between the adjacent loci. Of the 591 loci, 287, 302, and two were DArT-based, PCR-based, and morphological markers, respectively (Additional file 1: Table S3; Figure 1). The primer sets that amplified two or more loci were mapped to homoeologous and non-homoeologous sites. The six functional markers $A x 2^{*}, F M 1, G l u-b 3 h$, In10, STS01, and FM2 were accurately mapped to their corresponding chromosomes. $\mathrm{PPO} 33$, a functional marker for polyphenol oxidase (PPO-A1) on chromosome $2 \mathrm{AL}$, was mapped to chromosome $2 \mathrm{BL}$ in this genetic map. The two morphological markers coleocolor and leaftype were mapped to the short arms of chromosomes $3 \mathrm{~B}$ and $4 \mathrm{~B}$, respectively. Forty-one gaps greater than $40 \mathrm{cM}$ in length were distributed across 17 chromosomes except $2 \mathrm{~B}, 2 \mathrm{D}, 6 \mathrm{~B}$, and 6D (Figure 1). Nine gaps greater than $50 \mathrm{cM}$ in length remained on chromosomes $1 \mathrm{~A}, 1 \mathrm{~B}, 1 \mathrm{D}$, $2 \mathrm{~A}, 2 \mathrm{D}, 5 \mathrm{~A}, 5 \mathrm{~B}, 5 \mathrm{D}$, and $7 \mathrm{~A}$, whereas other chromosome arms were not covered (4DS, 5BS, and 6DL) (Figure 1).

Most markers were mapped to the B genome (44.8\%) and A genome (33.5\%), with an average of 37.9 and 28.3 markers per chromosome, respectively. The remaining markers $(21.7 \%)$ were mapped to the D genome, with an average of 18.3 markers per chromosome. Although the map lengths for each genome were very similar, the chromosome sizes ranged from $35.2 \mathrm{cM}$ (chromosome 4D) to $351.8 \mathrm{cM}$ (chromosome 2D), with an average of $187.2 \mathrm{cM}$ per chromosome. The number of markers on each chromosome ranged from two (chromosome 4D) to 61 (chromosome 1B), with a mean of 28.1 loci per chromosome. Chromosome $1 \mathrm{~B}$ had the highest average marker density (one marker per $3.1 \mathrm{cM}$ ), and chromosome 4D had the lowest average marker density (average of $17.6 \mathrm{cM}$ between adjacent loci) (Additional file 1: Table S3; Figure 1).

Forty-four (7.4\%) of the 591 loci were assigned to chromosomes different from those to which the loci had been assigned in previous reports (Table 1) [27,31] (http:// wheat.pw.usda.gov; http://wheat.pw.usda.gov/ITMI/E-SSR; http://www.triticarte.com.au). Interestingly, 21 (47.7\%) of these loci were remapped to the corresponding homoeologous chromosomes of the previous studies. In addition, eight (18.2\%) of these loci were reassigned to a chromosome that belonged to the same genomes (A, B, or D) as the chromosome to which they were assigned in the previous studies (Table 1).

In total, 194 (32.9\%) of the 589 molecular markers had previously been physically mapped to their corresponding chromosome bins [16,37-42]. The marker orders of loci from the present map were compared with those of previously published physical maps of bread or durum wheat. As shown in Figure 1, the orders were generally consistent. However, discrepancies in the marker orders 


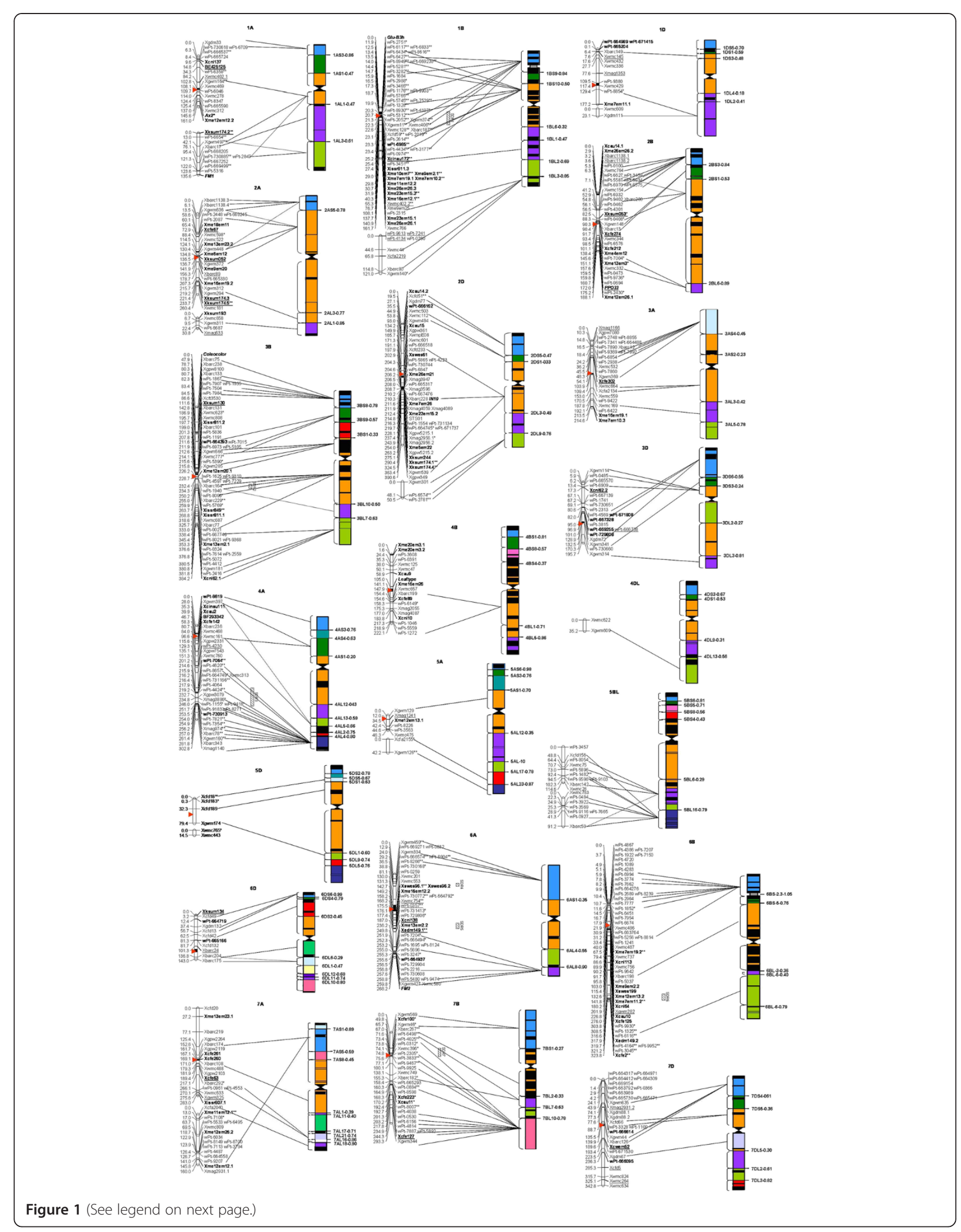


(See figure on previous page.)

Figure 1 Genetic map of wheat developed using an RIL population derived from the cross of the cultivars KN9204 and J411, and comparison of this novel map with previously developed physical maps of bread and durum wheat [16,20-25]. The approximate positions of centromeres are indicated by arrowheads. Short arms are at the top. The positions of the marker loci are listed to the left of the corresponding chromosomes. The names of the marker loci are listed to the right of the corresponding chromosomes. The lines show the genetic/physical relationships between markers found on both the novel genetic map and the previously compiled physical maps. If the physical bin of a marker locus was inconsistent in more than one previous study, we indicated all of the possible physical positions of the locus. Markers that exhibited distorted segregation were marked by $*(P<0.05)$ or $* *(P<0.01)$. Loci assigned to different chromosomes than those they were assigned to in previously compiled maps are underlined, and that are first reported in this map are marked by bold typeface.

were found on chromosomes 2BS, 3DS, 5BL, 7AL, 7BL, and 7DS.

Novel molecular markers and their chromosomal location Table 2 shows the chromosomal locations and genetic positions of the 17 novel DArT markers. These markers were assigned to chromosomes 1BS (one marker), 1DS (four markers), 2DS (one marker), 3BS (one marker), 3DS (four markers), 4AL (two markers), 6AL (one marker), 6DS (two markers), and 7D (two markers) by linkage analysis. We compared our genetic map with previously published physical maps and assigned 15 of these loci to 11 physical deletion bins (Figure 1, Table 2).

Fifty e-SSR-derived loci, 44 SRAP-derived loci, and five ISSR-derived loci were mapped for the first time on our map (Table 3, Figure 1). These markers were assigned to 18 chromosomes except 4D, 5B, and 5D. e-SSR primer pairs for KSUM174, CAU14, CNL62, and EDM149 each amplified multiple polymorphic loci that were mapped to homoeologous chromosomes. Two polymorphic loci amplified by the primer pairs for SWES96 were mapped to approximately the same position on chromosome 6AL. Sixteen $(61.5 \%)$ of the 26 SRAP primer pairs amplified two or three polymorphic loci, and $45.7 \%$ of these loci were mapped to chromosomes that belong to the same genomes (A, B or D). Finally, $60.6 \%$ of the novel loci were assigned to their corresponding physical deletion bins based on the comparison of the present genetic map with previous physical maps (Table 3, Figure 1).

\section{Segregation distortion}

On average, the 188 RILs inherited $49.5 \%$ of their alleles from the female parent (KN9204) and 50.05\% from the male parent (J411) (data not shown). This result shows that the population was skewed in favor of $3411\left(\chi^{2}=8.8\right.$, $\mathrm{P}<0.005)$. In total, $23.9 \%$ of the 591 loci significantly $(\mathrm{P}<0.05)$ deviated from a $1: 1$ ratio, and $15.23 \%$ of the loci exhibited distorted segregations at the $\mathrm{P}<0.01$ level (Additional file 1: Table S4). Of these, 56 (60.3\%) exhibited a segregation distortion in favor of J411 $(\mathrm{P}<0.05)$.

Table 1 Markers that were assigned to different chromosomes in previous studies

\begin{tabular}{|c|c|c|c|c|c|c|c|c|}
\hline Marker & Previous & Present & Marker & Previous & Present & Marker & Previous & Present \\
\hline BE425125 & $7 B$ & $1 \mathrm{AS}$ & Xksum 174.5 & $2 \mathrm{D} / 4 \mathrm{~B}$ & $2 \mathrm{AL}$ & wPt-0357 & $6 B$ & $6 \mathrm{AL}$ \\
\hline Xwmc402.1 & $7 B$ & $1 \mathrm{AS}$ & Xmag633 & $2 \mathrm{D}$ & $2 A L$ & Xcnl138 & $6 B$ & $6 \mathrm{AL}$ \\
\hline Xksum 174.2 & $2 \mathrm{D} / 4 \mathrm{~B}$ & $1 \mathrm{AL}$ & Xbarc1138.1 & $2 \mathrm{~A} / 2 \mathrm{D}$ & 2BS & Xedm149.1 & $5 B L / 6 B L$ & $6 \mathrm{AL}$ \\
\hline Xcinau172 & 2D/3B/4D/1R & $1 \mathrm{BS}$ & Xbarc1138.2 & $2 \mathrm{~A} / 2 \mathrm{D}$ & 2BS & $w P t-5480$ & $6 B$ & $6 \mathrm{AL}$ \\
\hline Xwmc402.2 & $7 B$ & $1 \mathrm{BS}$ & Xksum053 & $4 B$ & 2BS & Xgwm282 & $7 \mathrm{~A}$ & $6 \mathrm{BL}$ \\
\hline wPt-9613 & $5 B / 7 B$ & $1 \mathrm{BL}$ & Xcfe274 & $4 B$ & $2 \mathrm{BL}$ & Xksum134 & $4 \mathrm{~A}$ & 6DS \\
\hline wPt-7241 & $3 \mathrm{D} / 7 \mathrm{~B} / 6 \mathrm{R}$ & $1 \mathrm{BL}$ & PPO33 & $2 A L$ & $2 \mathrm{BL}$ & Xbarc24 & $6 \mathrm{BL}$ & 6DS \\
\hline$w P t-4134$ & $2 \mathrm{~B} / 3 \mathrm{D} / 7 \mathrm{~B}$ & $1 \mathrm{BL}$ & Xmag1166 & $3 B$ & $3 \mathrm{AS}$ & Xcfe63 & $7 B$ & $7 A L$ \\
\hline Xcfa2219 & $1 \mathrm{~A}$ & $1 \mathrm{BL}$ & Xcfe302 & $3 B$ & $3 A S$ & Xgwm325 & $5 B / 6 B / 6 D$ & $7 \mathrm{AL}$ \\
\hline Xwmc145 & $6 \mathrm{~A}$ & 1DS & Xksum 130 & $4 \mathrm{~A}$ & $3 B S$ & Xcfe127 & $3 B$ & $7 B L$ \\
\hline Xmag1353 & $4 \mathrm{~A}$ & 1DS & Xcnl62.2 & $3 B$ & $3 \mathrm{DS}$ & Xmag2931.2 & 4A/7A & 7DS \\
\hline Xсfe67 & $2 \mathrm{D}$ & $2 \mathrm{AS}$ & wPt-666738 & $3 B$ & $3 D S$ & Xcwem52 & $7 \mathrm{BL}$ & 7DL \\
\hline Xksum052 & $7 B$ & $2 \mathrm{AL}$ & $w P t-4230$ & $6 \mathrm{~B} / 7 \mathrm{~B}$ & $4 \mathrm{AL}$ & Xcfd5 & $5 B / 5 D / 6 D$ & 7DL \\
\hline Xbarc89 & $5 B L$ & $2 A L$ & Xmag1241 & $2 \mathrm{D}$ & $5 A S$ & Xwmc264 & $3 \mathrm{~A} / 5 \mathrm{D}$ & 7DL \\
\hline Xksum 174.3 & $2 \mathrm{D} / 4 \mathrm{~B}$ & $2 A L$ & Xwmc754 & $3 B$ & $6 \mathrm{AL}$ & & & \\
\hline
\end{tabular}

Relevant information on e-SSR markers with a CFE, CWEM, KSUM, or CNL is publicly available (http://wheat.pw.usda.gov/ITMI/E-SSR/). Relevant positional information on g-SSR markers, including those with a BARC, CFA, CFD, CFT, GWM, GDM, GPW, or WMC code, and on PCR-based STS markers with a MAG code, was obtained from the GrainGenes Web site (http://wheat.pw.usda.gov). Relevant information on DArT markers is publicly available (http://www.triticarte.com.au/). Information on the Xcinau172 and PPO33 loci was obtained from Zhuang et al. [27] and Liu et al. [31], respectively. 
Table 2 Novel DArT markers and their chromosomal locations

\begin{tabular}{|c|c|c|c|c|c|c|c|}
\hline Marker & Chr. & Position & Physical bin & Marker & Chr. & position & Physical bin \\
\hline WPt-6985 & 1BS & 23.3 & $1 \mathrm{BS} 10-0.50$ & wPt-729808 & $3 D S$ & 101.0 & 3DS6-0.55-1.0 \\
\hline wPt-664989 & 1DS & 0.0 & 1DS3-0.48-1.0 & wPt-7064 & $4 \mathrm{AL}$ & 201.2 & 4AL13-0.59-1.0 \\
\hline WPt-671415 & $1 \mathrm{DS}$ & 0.0 & 1DS3-0.48-1.0 & wPt-730913 & $4 \mathrm{AL}$ & 253.5 & 4AL4-0.80-1.0 \\
\hline WPt-665204 & $1 D S$ & 0.1 & 1DS3-0.48-1.0 & wPt-664937 & $6 \mathrm{AL}$ & 255.6 & 6AL8-0.90-1.0 \\
\hline wPt-666162 & $2 D S$ & 35.5 & 2DS1-0.33-1.0 & wPt-664719 & $6 \mathrm{DS}$ & 12.4 & 6DS6-0.99-1.0 \\
\hline WPt-664393 & $3 B S$ & 211.6 & 3BS9-0.57-0.78 & wPt-665166 & $6 \mathrm{DS}$ & 81.3 & - \\
\hline WPt-671808 & $3 D S$ & 82.0 & 3DS6-0.55-1.0 & wPt-666614 & 7DS & 88.7 & 7DS4-0.61-1.0 \\
\hline wPt-667328 & $3 D S$ & 82.0 & 3DS6-0.55-1.0 & wPt-666095 & $7 D L$ & 236.3 & - \\
\hline wPt-669255 & $3 D S$ & 96.9 & 3DS6-0.55-1.0 & & & & \\
\hline
\end{tabular}

'-': No available data.

Additionally, the DArT markers exhibited a higher proportion of distortion (27.53\%) than did the PCR-based markers $(20.53 \%)(\mathrm{P}<0.05)$.

The marker loci with distorted segregation were not randomly distributed. The marker loci on genome B exhibited a higher proportion of distortion (31.7\%) than did the loci on genomes A (23.2\%) and D (8.6\%) (Additional file 1: Table S4). Eighty-seven (61.7\%) marker loci with distorted segregation were clustered in seven SDRs on chromosomes 1B, 3BL, 4AL, 6AS, 6AL, 6BL, and 7B (Additional file 1: Table S5; Figure 1).

\section{Phenotypic performance and QTL for yield and response to $\mathrm{N}$ stress}

KN9204 showed similar YD to that of J411 in HN; in LN, the YD of KN9204 was higher than that of J411 (Table 4). In the 188 RILs, YD segregated continuously and generally followed a normal distribution in all environments, indicating that YD was a typical quantitative trait controlled by a few minor genes. The estimated broad-sense heritabilities of YD ranged from 33.32 to $82.95 \%$, which showed higher value in $\mathrm{HN}$ than that in LN. G $\times$ T interaction was significant at the 0.01 level in all trials. In analysis of variance based on combined data in $\mathrm{LN}$ and $\mathrm{HN}$, the genetic variance of YD accounted for $13.06-47.61 \%$ of the total variance. KN9204 showed lower YDDV than that of 5411 in all environments, indicating that KN9204 has a higher yield potential in LN (Table 5). YDDV was revealed the feature of a typical quantitative character with estimated broad-sense heritabilities ranging from 71.24 to $81.86 \%$ (Table 5).

A total of 22 and 12 QTLs for YD and YDDV were identified and were distributed in 16 chromosomes except 5A, 4D, 5D, 6D, and 7D (Table 6). These QTL individually accounted for $3.93-26.64 \%$ of the phenotypic variance with LOD values ranging from 1.65 to 5.17. Of these, $Q Y d-4 B .2$ and $Q Y d-7 B$ showed significance in four of the eight environments, individually exhibiting 4.66$16.91 \%$ and $5.12-6.08 \%$ of the phenotypic variance, respectively. In addition, $Q Y d-3 A$ and $Q Y d-6 B$ were reproducibly detected in three of the eight environments; QYd-1B.1 and QYd-4B.1 were identified in two of the eight environments. The remaining QTL for YD showed significance in only one of the eight environments. Of these, $Q Y d-2 D-1.1$ was approximately $4.0 \mathrm{cM}$ distal from IN10, one functional marker of GS2 gene. For YDDV, only $Q Y d d v-4 B$ was reproducibly detected in multiple environments, which individually accounting for 6.87$19.09 \%$ of the phenotypic variance with alleles from KN9204 decreasing YDDV (Table 6). It was noted that QYd-1A.2-1 and QYddv-1A.2, QYd-2A.1 and QYddv-2A.11, QYd-4B-2 and QYddv-4B, QYd-5B.2 and QYddv-5B.2-1, and $Q Y d-6 A$ and $Q Y d d v-6 A$ were pairwisely co-located, respectively. For YD, there were 13 QTL (59.10\%) with favorable alleles from KN9204 that increase YD. For YDDV, there were only two QTL (16.67\%) with favorable alleles from KN9204 that decrease YDDV. Interestingly, alleles of QYd-4B-2 from KN9204 increase YD in LN but decrease $\mathrm{YD}$ in $\mathrm{HN}$, and therefore it decrease YDDV, which was verified by the negative additive effect of $Q Y d d v-4 B$.

\section{Discussion}

The total map length and marker distribution across the wheat genome

Numerous molecular genetic maps covering the entire hexaploid genome of wheat have been compiled (Additional file 1: Table S6). These maps have described the hexaploid wheat genome as encompassing genetic distances ranging from $2260 \mathrm{cM}$ to $5332 \mathrm{cM}$. Sourdille et al. [38] suggested that the hexaploid wheat genome encompasses approximately $4000 \mathrm{cM}$ in the case of an intraspecific population. Certain studies have confirmed this finding, whereas other studies have produced maps covering <3500 cM (Additional file 1: Table S6). Interestingly, Gao et al. [7] developed an integrative map with a total length of $4641 \mathrm{cM}$, and Ganal and Röder [43] produced an integrative map encompassing $5332 \mathrm{cM}$ of the wheat genome. Nachit et al. [44] produced a durum 
Table 3 Novel e-SSR, ISSR, and SRAP markers, their chromosomal location, and PCR products

\begin{tabular}{|c|c|c|c|c|c|c|c|c|c|c|c|c|c|c|}
\hline Marker & Chr. & $\begin{array}{l}\text { Position } \\
\text { (cM) }\end{array}$ & $\begin{array}{c}\text { Alleles size } \\
\text { (Kn9204/J411) }\end{array}$ & $\begin{array}{l}\text { Physical } \\
\text { bin }\end{array}$ & Marker & Chr. & Position (cM) & $\begin{array}{c}\text { Alleles } \\
\text { (Kn9204/J411) }\end{array}$ & Physical bin & Marker & Chr. & $\begin{array}{l}\text { Position } \\
\text { (CM) }\end{array}$ & $\begin{array}{c}\text { Alleles } \\
(\text { Kn9204/J411) }\end{array}$ & Physical bin \\
\hline Xcn/137 & $1 \mathrm{AS}$ & 9.6 & $230 \mathrm{bp} / 240 \mathrm{bp}$ & - & Xme4em12 & $2 B \mathrm{~L}$ & 138.4 & 185 bp/Null & - & $x c n / 10$ & $4 \mathrm{BL}$ & 183.8 & $700 \mathrm{bp} / 710 \mathrm{bp}$ & C-4BL5-0.71 \\
\hline BE425125 & $1 \mathrm{AS}$ & 14.8 & 600 bp/Null & - & Xme13em3 & $2 \mathrm{BL}$ & 151.1 & 410 bp/Null & 2BL6-0.89-1.0 & Xme12em13.1 & $5 \mathrm{AS}$ & 11.8 & Null/85 bp & - \\
\hline Xme12em12.2 & $1 \mathrm{AL}$ & 161.0 & Null/210 bp & C-1AL1-0.47 & Xme12em26.1 & $2 \mathrm{BL}$ & 188.1 & Null/85 bp & 2BL6-0.89-1.0 & Xswes96.1 & $6 \mathrm{AL}$ & 142.7 & 400 bp/Null & - \\
\hline Xksum174.2 & $1 \mathrm{AL}$ & 0.0 & Null/285 bp & C-1AL1-0.47 & Xcau14.2 & 2DS & 0.0 & 130 bp/Null & 2DS5-0.47-1.0 & Xswes 96.2 & $6 \mathrm{AL}$ & 142.7 & Null/650 bp & - \\
\hline Xcinau172 & $1 \mathrm{BL}$ & 25.2 & $150 \mathrm{bp} / 180 \mathrm{bp}$ & - & Xcau15 & $2 \mathrm{DL}$ & 134.2 & 195 bp/200 bp & - & Xme16em12.2 & $6 \mathrm{AL}$ & 149.2 & 397 bp/Null & - \\
\hline Xissr811.3 & $1 \mathrm{BL}$ & 27.4 & Null/850 bp & 1BL1-0.47-1.0 & Xswes61 & $2 \mathrm{DL}$ & 202.9 & 300 bp/Null & $C-2 D\llcorner 3-0.49$ & Xcn/138 & $6 \mathrm{AL}$ & 187.0 & $200 \mathrm{bp} / 203 \mathrm{bp}$ & - \\
\hline Xmeroem7 & $1 \mathrm{BL}$ & 29.0 & 200 bp/Null & 1BL1-0.47-1.0 & Xme26em21 & $2 \mathrm{DL}$ & 206.2 & Null/198 bp & C-2DL3-0.49 & Xedm149.1 & $6 \mathrm{AL}$ & 249.8 & 202 bp/Null & - \\
\hline Xme9em 2.1 & $1 \mathrm{BL}$ & 29.0 & Null/ & 1BL1-0.47-1.0 & ne7em26 & $2 \mathrm{DL}$ & 211.6 & $150 \mathrm{bp} / 158 \mathrm{bp}$ & C-2DL3-0.49 & $m 2.2$ & $6 \mathrm{AL}$ & 236.2 & 160 & - \\
\hline Xme7em19.1 & $1 \mathrm{BL}$ & 29.0 & 103 bp/Null & 1BL1-0.47-1.0 & Xme23em15.2 & $2 \mathrm{DL}$ & 212.4 & 180 bp/Null & $C-2 D\llcorner 3-0.49$ & Xme7em 19.2 & $6 \mathrm{BS}$ & 67.5 & 210 bp/Null & - \\
\hline Xme7em10.2 & $1 \mathrm{BL}$ & 29.0 & 110 bp/Null & 1BL1-0.47-1.0 & Xme5em22 & $2 \mathrm{DL}$ & 254.0 & 103 bp/Null & C-2DL3-0.49 & Xcnl113 & $6 \mathrm{BS}$ & 86.6 & $250 \mathrm{bp} / 290 \mathrm{bp}$ & - \\
\hline Xmellem12.2 & $1 \mathrm{BL}$ & 29.8 & Null/386 bp & 1BL1-0.47-1.0 & Xksum244 & $2 \mathrm{DL}$ & 275.1 & Null/530 bp & C-2DL3-0.49 & Xmegem2.2 & $6 \mathrm{BL}$ & 103.0 & Null/200 bp & - \\
\hline Xme26em26.3 & $1 \mathrm{BL}$ & 30.7 & 185 & 1BL1-0.47-1.0 & $x$ & $2 \mathrm{DL}$ & 4 & $\mathrm{hon}$ & ل & 00 & $6 \mathrm{BL}$ & 115.4 & $200 \mathrm{hn} / 2$ & - \\
\hline Xme23em15.3 & $1 \mathrm{BL}$ & 31.9 & 400 bp/Null & 1BL1-0.47-1.0 & Xksum 174.4 & $2 \mathrm{DL}$ & 324.5 & Null/300 bp & $C-2 D L 3-0.49$ & Xme12em13.2 & $6 \mathrm{BL}$ & 132.6 & 108 bp/Null & - \\
\hline Xme16em12.1 & $1 \mathrm{BL}$ & 40.3 & Null/195 bp & 1BL1-0.47-1.0 & Xсfe302 & $3 A S$ & 54.1 & $285 \mathrm{bp} / 290 \mathrm{bp}$ & - & Xme7em11.2 & $6 \mathrm{BL}$ & 141.8 & Null/180 bp & - \\
\hline Xme9em 25 & $1 \mathrm{BL}$ & 76.7 & 210 bp/Null & 1BL1-0.47-1.0 & Xme16em19.1 & $3 A L$ & 213.5 & 98 bp/Null & 3AL3-0.42-1.0 & $x_{c n} 164$ & $6 \mathrm{BL}$ & 180.2 & $550 \mathrm{bp} / 480 \mathrm{bp}$ & - \\
\hline Xme23em15.1 & $1 \mathrm{BL}$ & 137.7 & 98 bp/Null & 1BL3-0.85-1.0 & Xme7em10.3 & $3 A L$ & 214.6 & 195 bp/Null & 3AL3-0.42-1.0 & Xcau10 & $6 \mathrm{BL}$ & 226.8 & $160 \mathrm{bp} / 175 \mathrm{bp}$ & - \\
\hline Xme26em26.1 & $1 \mathrm{BL}$ & 140.9 & Null/85 bp & 1BL3-0.85-1.0 & Xksum130 & $3 B S$ & 111.6 & 150 bp/Null & 3BS9-0.57-1.0 & Xcfe125 & $6 \mathrm{BL}$ & 276.0 & $428 \mathrm{bp} / 403 \mathrm{bp}$ & - \\
\hline Xme7em11.1 & $1 \mathrm{DL}$ & 177.2 & Null/160 bp & 1DL2-0.41-1.0 & Xissr811.2 & $3 \mathrm{BS}$ & 197.7 & 380 bp/Null & 3BS9-0.57-1.0 & Xedm149.2 & $6 \mathrm{BL}$ & 317.9 & Null/200 bp & $6 B L 5-0.4$ \\
\hline Xme18em11 & $2 A S$ & 65.4 & /Null & $C-$ & Xme12 & $3 B L$ & 226.2 & /Null & C-3BL10-0.50 & Xcfe2 & $6 \mathrm{BL}$ & 323.8 & $250 \mathrm{bp} / 254 \mathrm{bp}$ & 6BL5-0.40-1.0 \\
\hline Xсfe67 & $2 \mathrm{AS}$ & 72.9 & $280 \mathrm{bp} / 300 \mathrm{bp}$ & C-2AS5-0.78 & Xissr849 & $3 B \mathrm{BL}$ & 263.7 & 720 bp/Null & C-3BL10-0.50 & Xksum134 & $6 \mathrm{DS}$ & 0.0 & 260 bp/269 bp & 6DS6-0.99-1.0 \\
\hline Xme13em23.2 & $2 A S$ & 124.1 & Null/420 bp & C-2AS5-0.78 & Xissr811.1 & $3 B \mathrm{BL}$ & 268.8 & $280 \mathrm{bp} / 290 \mathrm{bp}$ & C-3BL10-0.50 & Xme13em23.1 & $7 A S$ & 27.2 & 200 bp/Null & - \\
\hline Xmeбem 12 & $2 A S$ & 134.8 & 110 bp/Null & C-2AS5-0.78 & Xme13em2.1 & $3 B \mathrm{BL}$ & 353.3 & Null/150 bp & 3BL7-0.63-1.0 & Xсfe261 & $7 A L$ & 167.1 & $280 \mathrm{bp} / 305 \mathrm{bp}$ & - \\
\hline Xksum052 & $2 A S$ & 136.5 & $400 \mathrm{bp} / 450 \mathrm{bp}$ & C-2AS5-0.78 & $X c n / 62.1$ & $3 B \mathrm{BL}$ & 384.2 & Null/480 bp & 3BL7-0.63-1.0 & Xcfe260 & $7 \mathrm{AL}$ & 169.1 & 300 & - \\
\hline Xme9em20 & $2 A S$ & 141.9 & 492 bp/Null & - & $X c n 162.2$ & 3DS & 17.3 & 590 bp/585 bp & - & Xcfe63 & $7 \mathrm{AL}$ & 189.4 & 380 bp/Null & - \\
\hline Xme16em19.2 & $2 \mathrm{AL}$ & 207.3 & Null/280 bp & - & Xcinau111 & $4 A S$ & 28.0 & 160 bp/Null & 4AS1-0.20-0.63 & Xissr807.1 & $7 A L$ & 283 & 240 bp/Null & 7AL21-0.74-1.0 \\
\hline Xksum174.3 & $2 \mathrm{AL}$ & 221.4 & 292 bp/Null & 2AL3-0.77-1.0 & Xcau2 & $4 \mathrm{AS}$ & 39.9 & $200 \mathrm{bp} / 206 \mathrm{bp}$ & 4AS1-0.20-0.63 & Xme11em12.1 & $7 \mathrm{AL}$ & 13.0 & 200 bp/Null & - \\
\hline Xksum 174.5 & $2 \mathrm{AL}$ & 233.7 & 398 bp/Null & 2AL3-0.77-1.0 & BF293342 & 4AS & 46.7 & 215 bp/Null & 4AS1-0.20-0.63 & Xme12em26.2 & $7 \mathrm{AL}$ & 118.7 & 295 bp/Null & - \\
\hline Xksum193 & $2 \mathrm{AL}$ & 0.0 & 203 bp/201 bp & 2AL3-0.77-1.0 & Xcfel42 & $4 A S$ & 58.3 & $160 \mathrm{bp} / 155 \mathrm{bp}$ & 4AS1-0.20-0.63 & Xme12em12.1 & $7 \mathrm{AL}$ & 145.8 & 121 bp/Null & - \\
\hline Xcau14.1 & $2 \mathrm{BS}$ & 0.0 & $180 \mathrm{bp} / 175 \mathrm{bp}$ & 2BS3-0.84-1.0 & Xme20em3.1 & $4 \mathrm{BS}$ & 0.0 & 85 bp/Null & - & Xcfe100 & $7 \mathrm{BS}$ & 49.8 & 470 bp/Null & 7BS1-0.27-1.0 \\
\hline Xme26em26.2 & $2 \mathrm{BS}$ & 2.9 & Null/135 bp & 2BS3-0.84-1.0 & Xmezoem3.2 & 4BS & 1.6 & Null/212 bp & - & Xcfe223 & $7 \mathrm{BL}$ & 168.3 & $203 \mathrm{bp} / 200 \mathrm{bp}$ & 7BL10-0.78-1.0 \\
\hline
\end{tabular}


Table 3 Novel e-SSR, ISSR, and SRAP markers, their chromosomal location, and PCR products (Continued)

\begin{tabular}{|c|c|c|c|c|c|c|c|c|c|c|c|c|c|c|}
\hline Xksum053 & $2 \mathrm{BS}$ & 82.5 & Null/300 bp & C-2BS1-0.53 & Xcau9 & $4 \mathrm{BS}$ & 58.9 & $215 \mathrm{bp} / 205 \mathrm{bp}$ & - & Xcau11 & $7 \mathrm{BL}$ & 170.2 & $190 \mathrm{bp} / 185 \mathrm{bp}$ & 7BL10-0.78-1.0 \\
\hline Xcfe274 & $2 \mathrm{BS}$ & 91.7 & 250 bp/Null & - & Xme16em26 & $4 \mathrm{BL}$ & 141.1 & Null/400 bp & - & Xсfe127 & $7 \mathrm{BL}$ & 244.3 & 430 bp/Null & 7BL 10-0.78-1.0 \\
\hline Xсfe212 & $2 \mathrm{BL}$ & 101.1 & 203 bp/209 bp & - & Xсfes9 & $4 \mathrm{BL}$ & 154.6 & $450 \mathrm{bp} / 500 \mathrm{bp}$ & $C-4 B L 5-0.71$ & Xcwem52 & $7 D L$ & 189.6 & $251 \mathrm{bp} / 249 \mathrm{bp}$ & - \\
\hline
\end{tabular}


Table 4 Phenotypic performance for yield

\begin{tabular}{|c|c|c|c|c|c|c|c|c|c|c|c|c|}
\hline \multirow{2}{*}{ En. $^{a}$} & \multirow{2}{*}{ Trial $^{b}$} & \multicolumn{2}{|c|}{ Parents (g) } & \multicolumn{9}{|c|}{ RIL } \\
\hline & & KN9204 & $J 411$ & Mean (g) & Range & Skewness & Kurtosis & $\mathrm{V}_{\mathrm{P} 1}{ }^{\mathrm{c}}$ & $\mathrm{V}_{\mathrm{G}} / \mathrm{V}_{\mathrm{P} 1}(\%)$ & $V_{P 2}{ }^{d}$ & $\mathrm{~V}_{\mathrm{G} \times \mathrm{T}} / \mathrm{V}_{\mathrm{P} 2}{ }^{\mathrm{e}}(\%)$ & $\mathrm{V}_{\mathrm{G}} / \mathrm{V}_{\mathrm{P} 2}(\%)$ \\
\hline \multirow{2}{*}{ E1 } & $\mathrm{LN}$ & $8.13^{* *}$ & 7.24 & 6.57 & 7.68 & 0.27 & 1.18 & 2.11 & $33.32^{* *}$ & \multirow{2}{*}{3.54} & \multirow{2}{*}{$39.38^{* *}$} & \multirow{2}{*}{$20.31^{* *}$} \\
\hline & $\mathrm{HN}$ & 10.37 & 10.35 & 10.03 & 10.17 & -0.01 & -0.46 & 5.07 & $69.53^{* *}$ & & & \\
\hline \multirow{2}{*}{ E2 } & LN & $4.92^{* *}$ & 3.62 & 5.58 & 7.57 & 0.40 & -0.12 & 2.85 & $55.52^{* *}$ & \multirow{2}{*}{7.53} & \multirow{2}{*}{$58.22^{* *}$} & \multirow{2}{*}{$13.06^{* *}$} \\
\hline & $\mathrm{HN}$ & 14.30 & 14.28 & 13.28 & 18.74 & 0.31 & 0.37 & 12.22 & $74.93^{* *}$ & & & \\
\hline \multirow{2}{*}{ E3 } & LN & $9.87^{*}$ & 9.45 & 9.08 & 9.74 & -0.31 & 0.72 & 2.77 & $50.75^{* *}$ & \multirow{2}{*}{4.13} & \multirow{2}{*}{$34.78^{* *}$} & \multirow{2}{*}{$37.19^{* *}$} \\
\hline & $\mathrm{HN}$ & 11.27 & 11.75 & 12.18 & 17.92 & 0.93 & 4.41 & 6.17 & $73.53^{* *}$ & & & \\
\hline \multirow{2}{*}{ E4 } & LN & 9.97 & 9.93 & 9.04 & 11.33 & 0.09 & 0.04 & 4.73 & $78.47^{* *}$ & \multirow{2}{*}{5.73} & \multirow{2}{*}{$33.69^{* *}$} & \multirow{2}{*}{$47.61^{* *}$} \\
\hline & HN & 11.65 & 11.85 & 10.93 & 14.11 & 0.04 & -0.13 & 6.75 & $82.95^{* *}$ & & & \\
\hline
\end{tabular}

${ }^{\mathrm{a}}$ En. = environments.

${ }^{\mathrm{b}} \mathrm{LN}$ and $\mathrm{HN}$ denote low nitrogen treatment and high nitrogen treatment, respectively.

'Phenotypic variance for yield in each of the individual trial of $\mathrm{LN}$ or $\mathrm{HN}$.

${ }^{d}$ Phenotypic variance for yield in each of the combined trial of LN and HN.

${ }^{\mathrm{e}}$ Genetic by $\mathrm{N}$ treatment interaction variance in each of the combined trial of LN and HN.

**Difference is significant when $\mathrm{p}<0.01$ level; *Difference is significant when $\mathrm{p}<0.05$ level.

wheat $(\mathrm{AABB}, 2 \mathrm{n}=4 \mathrm{X}=28)$ map spanning $3598 \mathrm{cM}$ using an intraspecific RIL mapping population. These reports imply that it is possible to produce a molecular genetic map spanning $>5000 \mathrm{cM}$ for allohexaploid bread wheat using a large intraspecific population and various types of molecular markers.

In the present study, we produced a novel molecular genetic map for wheat based on various types of molecular and morphological markers. This map encompassed $5257 \mathrm{cM}$ of the wheat genome, including 31 gaps with a linkage distance greater than $40 \mathrm{cM}$ but less than $50 \mathrm{cM}$. This map length corresponded to that of an integrative map reported by Ganal and Röder [43]. To the best of our knowledge, this is the longest molecular genetic map of common wheat based on an individual intraspecific mapping population. The moderate mapping population size (188 lines) and the variety of molecular markers that were mapped might explain the completeness and length of this genetic map. Including the 31 large gaps with a distance of more than $40 \mathrm{cM}$ would have resulted in an overestimation of the total map length, as the LOD values for pairwise loci with a distance of $>40 \mathrm{cM}$ were relatively low (approximately 2.5). Therefore, when excluding the 31 large gaps from the count of the total map length, we produced a map with a total length of
3931 cM, which is comparable to the length of the map produced by Sourdille et al. [38].

A lower number of polymorphisms in the $\mathrm{D}$ genome than in the A and B genomes has been documented and is consistent with the hypothesis of a monophyletic introduction of the D genome in bread wheat [45]. Almost all of the previously compiled genetic maps of allohexaploid bread wheat listed in the additional file (Additional file 1: Table S6) mapped fewer marker loci in the D genome than in the A and B genomes, especially on chromosome 4D. In the present map, the $\mathrm{D}$ genome contains only $21.7 \%$ of all loci, and chromosome 4D contains only two g-SSR markers, which is consistent with the findings of previous reports. However, the achieved map coverage was almost identical for the three genomes, which is also consistent with previous reports.

\section{Comparison of the present genetic map with previous physical maps}

To date, many molecular markers, including RFLP, g-SSR, e-SSR, STS, and DArT markers have been physically mapped [16,37-42]. One hundred ninety-four (32.9\%) of the 589 molecular markers mapped in the present study had previously been physically mapped to their corresponding chromosome bins; this information allowed

Table 5 Phenotypic performance for yield difference between the value under HN and the value under LN

\begin{tabular}{|c|c|c|c|c|c|c|c|c|c|}
\hline \multirow{2}{*}{ En..$^{a}$} & \multicolumn{2}{|c|}{ Parents (g) } & \multicolumn{7}{|c|}{$R I L$} \\
\hline & KN9204 & $J 411$ & Mean (g) & Range (g) & $V_{P}$ & Std & Skewness & Kurtosis & $\mathrm{V}_{\mathrm{G}} / \mathrm{V}_{\mathrm{P}}(\%)$ \\
\hline E1 & 2.24 & 3.11 & 3.46 & 7.63 & 4.83 & 2.05 & -0.21 & -0.41 & $74.67^{* *}$ \\
\hline E2 & 9.33 & 10.66 & 7.70 & 18.81 & 12.14 & 3.31 & 0.41 & 0.51 & $80.52^{* *}$ \\
\hline E3 & 1.40 & 2.30 & 3.10 & 11.13 & 4.77 & 2.01 & 0.61 & 1.21 & $71.24^{* *}$ \\
\hline E4 & 1.68 & 1.92 & 1.89 & 8.68 & 5.43 & 2.22 & -0.20 & 0.50 & $81.86^{* *}$ \\
\hline
\end{tabular}

${ }^{\mathrm{a}}$ En. = environments.

**Difference is significant when $p<0.01$ level. 
Table 6 Putative QTL with significant additive effects for YD and YDDV

\begin{tabular}{|c|c|c|c|c|c|c|}
\hline$\overline{Q T L^{a}}$ & Position $^{a}$ & Flanking marker ${ }^{a}$ & Trial & $\angle O D$ & Add. $^{b}$ & PVE\% $^{c}$ \\
\hline QYd-1A.1 & 15 & BE425125—wPt-6358 & $\mathrm{E} 4-\mathrm{HN}$ & 2.82 & -0.57 & 5.27 \\
\hline$Q Y d-1 A .2-1$ & 0 & Xksum174.2-wPt-6654 & $\mathrm{E} 1-\mathrm{HN}$ & 3.48 & 0.73 & 8.17 \\
\hline$Q Y d d v-1 A .2$ & 0 & Xksum174.2-wPt-6654 & E1 & 1.84 & 0.53 & 4.41 \\
\hline QYd-1A.2-2 & 121 & wPt-668205-wPt-667252 & E3-LN & 1.85 & -0.30 & 4.54 \\
\hline QYd-1B.1 & $23 / 28$ & $w P t-2751-w P t-2614$ & E4-LN/E4-HN & $4.33 / 1.99$ & $-0.78 /-0.42$ & $8.54 / 4.03$ \\
\hline QYd-1D.1-1 & 109 & Xmag1353-wPt-9380 & E4-LN & 1.90 & 0.40 & 3.65 \\
\hline QYd-1D.1-2 & 177 & wPt-8854-Xme7em 11.1 & E3-LN & 2.03 & 0.33 & 4.91 \\
\hline QYd-2A.1 & 124 & Xwmc522-Xme13em 23.2 & E3-HN & 1.85 & 0.44 & 3.89 \\
\hline QYddv-2A.1-1 & 130 & Xme13em23.2-Xgwm448 & E2 & 1.95 & 0.69 & 4.31 \\
\hline QYddv-2A.1-2 & 164 & Xbarc98-wPt-665330 & E3 & 1.81 & 0.53 & 6.82 \\
\hline$Q Y d d v-2 B$ & 6 & wPt-0100—Xwmc764 & E3 & 2.10 & -0.45 & 5.10 \\
\hline$Q Y d-2 B$ & 86 & Xksum053—wPt-0408 & $\mathrm{E} 1-\mathrm{HN}$ & 2.50 & 0.56 & 8.17 \\
\hline QYddv-2D.1 & 77 & Xwmc112-Xgwm484 & E4 & 1.85 & 0.77 & 11.93 \\
\hline QYd-2D.1-1 & 206 & Xmag3956-IN10 & E2-LN & 2.21 & 0.34 & 5.27 \\
\hline QYd-2D.1-2 & 332 & Xksum174.4-Xgwm539 & E2-LN & 2.01 & 0.50 & 10.81 \\
\hline QYd-3A & 103/100/120 & Xcfe302-Xwmc559 & E2-HN/E4-LN/E4-HN & $1.68 / 2.63 / 3.16$ & $0.56 / 0.85 / 1.02$ & $8.32 / 17.03 / 16.63$ \\
\hline$Q Y d-3 B$ & 117 & Xksum130-Xbarc131 & $\mathrm{E} 4-\mathrm{HN}$ & 2.43 & -0.64 & 6.69 \\
\hline QYd-3D & 5 & Xgwm114-wPt-0485 & E3-HN & 3.24 & -0.61 & 7.30 \\
\hline QYddv-3D-1 & 68 & wPt-1741—wPt-730651 & E4 & 2.11 & 0.51 & 5.33 \\
\hline$Q Y d d v-3 D-2$ & 100 & wPt-666738—wPt-729808 & E4 & 2.12 & 0.51 & 5.34 \\
\hline QYd-4A-1 & 47 & BF293342-Xcfe142 & E2-LN & 2.12 & 0.42 & 4.06 \\
\hline QYd-4A-2 & 103 & Xwmc161-Xgpw2331 & E1-LN & 2.42 & -0.34 & 8.66 \\
\hline QYd-4B-1 & $50 / 54$ & Xwmc125-Xcau9 & E4-LN/E4/HN & $4.91 / 3.57$ & $0.65 / 0.70$ & $10.01 / 7.90$ \\
\hline QYd-4B-2 & $202 / 184 / 188 / 181$ & Xwmc657-wPt-1046 & E2-LN/E2-HN/E3-HN/E4-LN & $2.61 / 2.94 / 2.23 / 2.15$ & $0.62 /-0.87 /-0.60 / 0.44$ & $16.91 / 7.06 / 7.03 / 4.66$ \\
\hline$Q Y d d v-4 B$ & $190 / 174$ & Xwmc657-wPt-1046 & E2/E3 & $5.17 / 5.05$ & $-1.45 /-0.45$ & $19.09 / 6.87$ \\
\hline QYd-5B.2 & 0 & Xwmc783-wPt-0408 & E1-HN & 1.96 & 0.43 & 4.29 \\
\hline$Q Y d d v-5 B .2-1$ & 0 & Xwmc783-wPt-0408 & E1 & 1.85 & 0.43 & 4.44 \\
\hline QYddv-5B.2-2 & 42 & wPt-0927-Xbarc59 & E2 & 2.31 & 0.75 & 5.13 \\
\hline$Q Y d-6 A$ & 259 & wPt-9474-Xwmc580 & E2-LN & 1.89 & -0.32 & 4.54 \\
\hline$Q Y d d v-6 A$ & 236 & Xcnl138-Xme13em2.2 & E3 & 1.89 & 0.43 & 4.60 \\
\hline QYd-6B & $22 / 22 / 22$ & Xwmc486—wPt-663764 & E2-LN/E4-LN/E4-HN & $1.70 / 2.54 / 2.25$ & $0.38 / 0.46 / 0.49$ & $4.25 / 5.04 / 3.93$ \\
\hline
\end{tabular}


Table 6 Putative QTL with significant additive effects for YD and YDDV (Continued)

\begin{tabular}{lccccc}
\hline QYddV-7A.2 & 39 & wPt-7108-wPt-6495 & E1 & 1.89 & $\mathbf{2 6}$ \\
QYd-7A.2 & 150 & Xme12em12.1-Xmag2931.1 & E4-LN & 3.15 & -0.60 \\
QYd-7B & $75 / 80 / 76 / 73$ & $X c f e 100-w P t-9467$ & E2-HN/E3-LN/E3-HN/E4-LN & $1.52 / 2.05 / 2.77 / 1.65$ & $0.30 / 0.36 / 0.58 / 0.31$ \\
\hline
\end{tabular}

aYD: Yield per plant; YDDV: yield difference between the value under HN and the value under LN. Co-located QTL for YD and YDDV was marked by bold typeface.

bPVE: Phenotypic variance explained by the corresponding putative additive QTL; PVE\% that was > $10 \%$ was marked by bold typeface.

CAdditive effect of the corresponding putative additive QTL; positive values indicate KN9204 alleles that increase the value of the corresponding trait, and, conversely, negative values indicate KN9204 alleles that Additive effect 
us to evaluate the colinearity of the markers and thus directly support fine mapping of major QTLs and mapbased gene cloning.

Although the chromosome assignments produced in this study are largely in agreement with previously published mapping information, discrepancies remained for $44(7.4 \%)$ of the 591 loci (Table 1). Of these, 21 (47.7\%) markers were mapped at positions homoeologous to the positions reported in previous maps. In addition, eight (18.2\%) loci were mapped to chromosomes that belonged to the same genomes (genomes A, B, or D) as the chromosome to which these loci were mapped in previous studies. The relative order of markers within linkage groups in the present map was largely consistent with the order of markers found in previously published physical maps. However, discrepancies remained for chromosomes 2BS, 3DS, 5BL, 7AL, 7BL, and 7DS (Figure 1). Inaccurate genotyping for these markers were excluded by carefully checking the marker scores. However, these discrepancies remained. These markers might be multilocus markers, and the novel polymorphic sequence on other chromosomes or the same chromosome was detected and mapped in this population. In addition, chromosomal rearrangement such as interchromosomal/intrachromosomal translocation or paracentric inversion might explain these discrepancies. Further studies are necessary to confirm this hypothesis.

A vast majority of recombination events occur on the most distal portions of the chromosomal arms in wheat; recombination events around the centromere tend to be suppressed $[37,46]$. Previous studies have supported the idea that large genetic distances in the centromeric region on genetic maps correspond to small genetic distances on physical maps [16,37-42]. A comparison of the present genetic map with previously published physical maps confirmed this conclusion. For example, four markers spanning $>170 \mathrm{cM}$ in the distal portion of chromosomal arm $1 \mathrm{BL}$ accounted for only $15 \%$ of the length of the $1 \mathrm{BL}$ arm; nine markers spanning approximately $50 \%$ of the distal portion of the $2 \mathrm{BS}$ arm in the genetic map accounted for only $16 \%$ of the $2 \mathrm{BS}$ arm in the physical map; and fourteen markers spanning approximately $37 \%$ of the distal portion of the 4AL arm in the genetic map accounted for $20 \%$ of the $4 \mathrm{AL}$ arm in the physical map. Finally, twelve markers spanning approximately $90 \%$ of the distal portion of the $7 \mathrm{BL}$ arm in the genetic map accounted for only $22 \%$ of the 7BL arm in the physical map (Figure 1).

\section{Novel markers and multilocus markers}

e-SSRs are more transferable between species than microsatellites derived from genomic libraries [6,47]. SRAPs and ISSRs have characteristics that are not species specific. Moreover, e-SSRs and SRAPs are generally directly related to functional genes $[9,11]$. To date, few SRAP and e-SSR markers have been integrated into wheat SSR maps $[4,5,7,48]$. In the present study, we provided detailed information on the chromosomal locations of 17 DArT, 50 e-SSR, 44 SRAP, and five ISSR markers (Tables 2, 3; Figure 1). We also presented the positions and orders of these markers relative to those of the g-SSRs, in addition to the size of the allele in the two mapping parents and the estimated corresponding physical bins when possible (Table 3). This information facilitates the use of these markers in wheat molecular breeding programs and genomics research.

Aneuploidy and linkage analyses have previously shown that the three genes controlling the red coleoptile color ( $R c 1, R c 2$ and $R c 3$ ) are located on chromosomes 7A, 7B, and 7D, respectively [49-52]. The morphological markers for the coleoptile color (the coleocolor locus) and flag leaf type (the leaftype locus) segregated as Mendelian factors in the RIL population and mapped to $3 \mathrm{BS}$ and 4BS, respectively (Figure 1). Therefore, the coleocolor locus may harbor a novel gene controlling the coleoptile color. To the best of our knowledge, no other reports have mapped the genes that control the flag leaf type to the 4BS chromosome arm of wheat.

Although SSR and STS markers are believed to be locus-specific, several primer pairs amplified more than one fragment in this study $[3,53]$. It is noted that multiple loci identified by certain e-SSR, g-SSR, and STS markers in allohexaploid wheat were apt to be mapped to homoeologous positions. This finding is consistent with the polyploidy, synteny and homoeology of the three genomes (A, B, and D) [54-56]. In total, $45.7 \%$ of the 44 loci amplified by 16 SRAP primer pairs were pairwisely mapped to chromosomes that belong to the same genome (A, B or D) rather than to homoeologous positions. The remaining loci amplified by specific SRAP primer pairs were scattered among the wheat genomes (Table 3, Figure 1). As an ORF-based marker system that targets functional genes, SRAPs have multilocus, multi-allelic, and non-specific characteristics among genomes and species [11]. These features might explain the abovementioned findings.

\section{Segregation distortion}

Segregation distortion is a common phenomenon that can be influenced by chromosomal rearrangements, alleles inducing gametic or zygotic selection, parental reproductive differences, the presence of lethal genes, and environment factors [44,49,57-60]. A biological segregation distortion locus can cause the locus of interest and the flanking regions to deviate from the expected Mendelian segregation ratio, thus forming an SDR $[57,61,62]$.

In the present study, seven SDRs on chromosomes $1 \mathrm{~B}$, $3 \mathrm{BL}, 4 \mathrm{AL}, 6 \mathrm{AS}, 6 \mathrm{AL}, 6 \mathrm{BL}$, and 7B were identified; these SDRs might have been produced by biological factors 
(Additional file 1: Table S5). Previous studies have also reported the presence of SDRs in these chromosomal regions $[15,44,48,49,56,63]$. It is noteworthy that $42(29.8 \%)$ loci with distorted segregation were clustered on the SDR1 of chromosome 1B, which may be related to 1 RS in parental line KN9204. Approximately $38 \%$ and $62 \%$ of the 188 RILs contain 1 RS and 1BS, respectively, which is consistent with our previous three RIL populations (WL, WY, and WJ) [19]. This finding suggests that the normal 1B chromosomes are more capable of being preferentially transmitted through the male and female gametes than are the unbalanced chromosomes of 1BL/1RS.

QTL for yield and its response to $\mathrm{N}$ stress: their use in wheat molecular breeding programs

Alleles of QTL that increase YD in LN are of value in wheat breeding programs designed to increases NUE. In this study, $Q Y d-1 D-1.1, Q Y d-1 D-1.2, Q Y d-$ 2D-1.1, QYd-2D-1.2, QYd-3A, QYd-4A-1, QYd-4A-2,
$Q Y d-4 B-2, Q Y d-6 B$, and $Q Y d-7 B$ showed positive additive effects that increase $Y D$ in $L N$, indicating that alleles from KN9204 of these QTL are elite alleles (Table 6). QYd-1A-2.2, QYd-1B.1, QYd-4A.2, $Q Y d-6 A$ and $Q Y d-7 A .2$ showed negative additive effects in LN, indicating that alleles from J411 of these QTL increase YD in LN (Table 6). Pyramiding these elite alleles in wheat molecular breeding programs might be an optimal war to improve NUE and thus increase YD potential under LN.

Low input agricultural practices, particularly LN input management requires varieties that are insensitive to $\mathrm{N}$ stress. YDDV could be used as a 'global' interaction variable to estimate the response of YD to N stress [21]. Decreasing alleles of QTL for YDDV can increase Ndeficiency tolerance and thus can maintain yield under $\mathrm{N}$ stress. In this study, there were two and ten QTL with favorable alleles that decrease YDDV from KN9204 and J411, respectively. Therefore, we should pyramid these

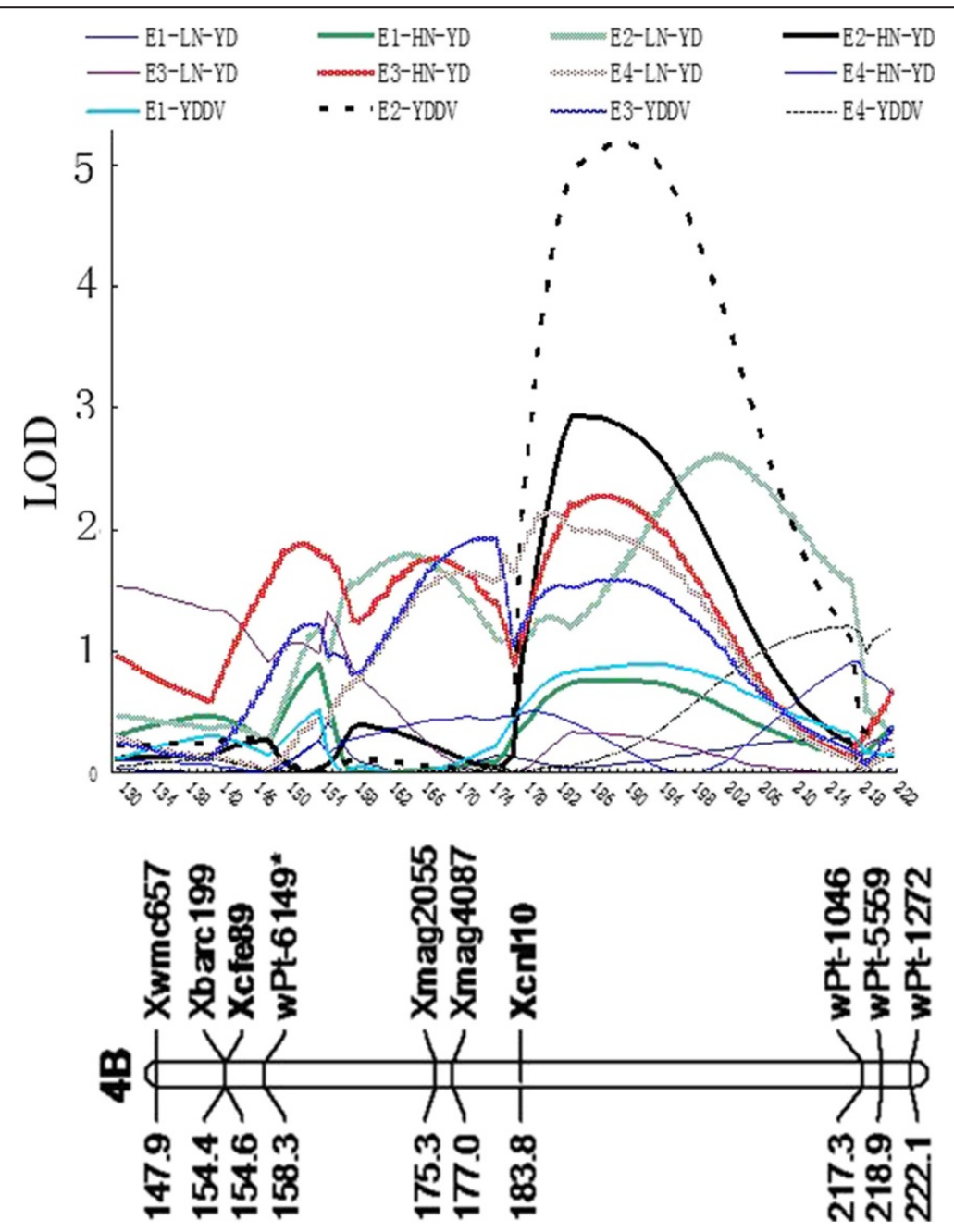

Figure 2 The LOD value scanning of major stable QTL $Q Y d-4 B-2$ and $Q Y d d v-4 B$ in the eight individual environments. 
elite alleles in wheat molecular breeding programs to improve $\mathrm{N}$ stress tolerance.

The conserved genomic regions harboring major stable QTL are valuable for MAS in breeding programs. $Q Y d-4 B-2$ and $Q Y d d v-4 B$ shared support interval, and they both exhibited significance in multiple environments (Table 6, Figure 2). For YD and YDDV in all environments, the LOD curves peaked at approximately similar position of the Xcnl10-wPt-1046 region, albeit some LOD values were relatively lower than the threshold (Figure 2). Interestingly, alleles of $Q Y d-4 B-2$ from KN9204 could increase YD in LN with positive additive effects of $0.62 \mathrm{~g}$ and $0.44 \mathrm{~g}$; $Q Y d d v-4 B$ from KN9204 with negative effect of $-1.45 \mathrm{~g}$ and $-0.45 \mathrm{~g}$ accounted for 19.09 and $6.87 \%$ of the phenotypic variance in E2 and E3, respectively. Unfortunately, limited polymorphic markers were available in this region; consequently, these two major stable QTLs resided on a relatively large confidence interval. More markers should be enriched in this region with the aim to finely map these QTLs and provide available markers for MAS. To date, information on the sequences of numerous bin-mapped wheat ESTs and scaffolds is publicly available [1,2] (http://wheat.pw.usda. gov/wEST/binmaps/). The relative physical bins of the Xcnl10-wPt-1046 region are estimated in Figure 1, which will facilitate the fine mapping or even map-based cloning of this QTL.

\section{Conclusion}

We developed a novel genetic map with g-SSR, e-SSR, DArT, STS, SRAP, ISSR, and morphological markers distributed across 21 wheat chromosomes spanning $3930.7 \mathrm{cM}$. The linear relationships between loci found in the present map and in previously compiled physical maps were specified. We also presented information on the genetic and physical positions and allele sizes (when possible) for 17 DArT, 50 e-SSR, 44 SRAP, five ISSR, and two morphological markers. Seven SDRs were identified on chromosomes $1 \mathrm{~B}, 3 \mathrm{BL}, 4 \mathrm{AL}, 6 \mathrm{AS}$, 6AL, 6BL, and 7B. A total of 22 and 12 QTL for YD and YDDV were identified, respectively. Of these, $Q Y d$ $4 B-2$ and $Q Y d d v-4 B$, two major stable QTL, shared support interval with alleles from KN9204 increasing YD in LN and decreasing YDDV. We probe into the use of these QTL in wheat breeding programs. In addition, factors affecting the occurrence of SDRs and the total map length were discussed in depth. This novel map facilitates the use of novel markers in wheat molecular breeding programs and genomics research. Moreover, QTL for YD and YDDV provide useful markers for wheat molecular breeding programs designed to increase yield potential under $\mathrm{N}$ stress.

The data sets supporting the results of this article are included within the article and its Additional file 1.

\section{Additional file}

Additional file 1: Table S1. Polymorphic primer sequences for ISSR and SRAP markers. Table S2. Summary of the year, location and nitrogen treatment conditions in our study. Table S3. Density and distribution of markers in the novel genetic map of wheat. Table S4. Marker loci with distorted segregation and their distribution in the wheat genome. Table S5. Distribution of seven distorted chromosomal regions. Table S6. A comparison of map lengths (cM) of various linkage maps of the wheat genome generated in different mapping populations.

\section{Abbreviations}

QTL: Quantitative trait loci; YD: Yield per plant; YDDV: Yield difference between the value under high nitrogen treatment and the value under low nitrogen treatment; g-SSR: Genomic simple sequence repeat;

e-SSR: Expressed sequence tag-derived microsatellite; DArT: Diversity arrays technology; STS: Sequence-tagged sites; SRAP: Sequence-related amplified polymorphism; ISSR: Inter-simple sequence repeat; N: Nitrogen; HN: High nitrogen treatment; LN: Low nitrogen treatment; RIL: recombinant inbred line population; KN9204: Kenong9204; J411: Jing411; KJ-RILs: Recombinant inbred line population derived from the cross between Kenong9204 and Jing411; ORFs: Open reading frames; MAS: Marker-assisted selection; SDR: Segregation distortion region; NUE: Nitrogen use efficiency; LOD: Logof-odds.

\section{Competing interests}

The authors declare that they have no competing interests.

\section{Author' contributions}

$\mathrm{CF}, \mathrm{FXL}, \mathrm{ZCH}$, and $\mathrm{CM}$ performed the genotyping and phenotyping of the parental lines and KJ-RILs. CF and FXL performed the linkage analysis and constructed the map. CF drafted the manuscript, and LJM, JJ, and ZW provided a critical review of the manuscript. LJM and JJ constructed the KJ-RIL population. All authors approved the final version of the manuscript.

\section{Acknowledgments}

This research was supported by grants from the Ministry of Science and Technology of China (No. 2011CB100104), the Chinese Academy of Sciences (No. KSCX2-EW-N-02) and the Ministry of Agriculture of China (No. CARS-03-03B).

\section{Author details}

${ }^{1}$ Center for Agricultural Resources Research, Institute of Genetics and Developmental Biology, Chinese Academy of Sciences, Shijiazhuang 050022, China. ${ }^{2}$ State Key Laboratory of Plant Cell and Chromosome Engineering, Chinese Academy of Sciences, Beijing 100101, China. ${ }^{3}$ University of Chinese Academy of Sciences, Beijing 10049, China.

Received: 1 April 2014 Accepted: 9 May 2014

Published: 15 May 2014

\section{References}

1. Jia J, Zhao S, Kong X, Li Y, Zhao G, He W, Appels R, Pfeifer M, Tao Y, Zhang X, Jing R, Zhang C, Ma Y, Gao L, Gao C, Spannagl M, Mayer KFX, Li D, Pan S, Zheng F, Hu Q, Xia X, Li J, Liang Q, Chen J, Wicker T, Gou C, Kuang H, He G, Luo $Y$, et al: The Aegilops tauschii draft genome sequence reveals a gene repertoire for wheat adaptation. Nature 2013, 496:91-95.

2. Ling H, Zhao S, Liu D, Wang J, Sun H, Zhang C, Fan H, Li D, Dong L, Tao Y, Gao C, Wu H, Li Y, Cui Y, Guo X, Zheng S, Wang B, Yu K, Liang Q, Yang W, Lou X, Chen J, Feng M, Jian J, Zhang X, Luo G, Jiang Y, Liu J, Wang Z, Sha Y, et al: Draft genome of the wheat A-genome progenitor Triticum urartu. Nature 2013, 496:87-90.

3. Röder MS, Korzum V, Gill BS, Ganal MW: The physical mapping of microsatellite markers in wheat. Genome 1998, 41:278-283.

4. Yu JK, Dake TM, Singh S, Benscher D, Li W, Gill B, Sorrells ME: Development and mapping of EST-derived simple sequence repeat markers for hexaploid wheat. Genome 2004, 47:805-818.

5. Li SS, Jia JZ, Wei XY, Zhang XC, Li LZ, Chen HM, Fan YD, Sun HY, Zhao XH, Lei TD, Xu YF, Jiang FS, Wang HG, Li LH: A intervarietal genetic map and QTL analysis for yield traits in wheat. Mol Breed 2007, 20:167-178. 
6. Chabane K, Varshney RK, Graner A, Valkoun J: Generation and exploitation of EST-derived SSR markers for assaying molecular diversity in durum wheat populations. Genet Resour Crop Evol 2008, 55:869-881.

7. Gao LF, Jing RL, Huo NX, Li Y, Li XP, Zhou RH, Chang XP, Tang JF, Ma ZY, Jia JZ: One hundred and one new microsatellite loci derived from ESTs (E-SSR) in bread wheat. Theor App/ Genet 2004, 108:1392-1400.

8. Zietkiewicz E, Rafalski A, Labuda D: Genome fingerprinting by simple sequence repeat (SSR)-anchored polymerase chain reaction amplification. Genomics 1994, 20:176-183.

9. Nagaoka T, Ogihara Y: Applicability of inter-simple sequence repeat polymorphisms in wheat for use as DNA markers in comparison to RFLP and RAPD markers. Theor Appl Genet 1997, 94:597-602.

10. Li G, Quiros CF: Sequence-related amplified polymorphism (SRAP), a new marker system based on a simple PCR reaction: its application to mapping and gene tagging in Brassica. Theor App/ Genet 2001, 103:455-461.

11. Aneja B, Yadav NR, Chawla V, Yadav RC: Sequence-related amplified polymorphism (SRAP) molecular marker system and its applications in crop improvement. Mol Breed 2012, 30:1635-1648.

12. Akbari M, Wenzl P, Caig V, Carling J, Xia L, Yang S, Uszynski G, Mohler V, Lehmensiek A, Kuchel H, Hayden MJ, Howes N, Sharp P, Vaughan P, Rathmell B, Huttner E, Kilian A: Diversity arrays technology (DArT) for high-throughput profiling of the hexaploid wheat genome. Theor Appl Genet 2006, 113:1409-1420.

13. Semagn K, Bjørnstad A, Skinnes H, Marøy AG, Tarkegne $Y$, William M: Distribution of DArT, AFLP and SSR markers in a genetic linkage map of a double haploid hexaploid wheat population. Genome 2006, 49:545-555.

14. Mantovani $P$, Maccaferri M, Sanguineti MC, Tuberosa R, Catizone I, Wenzl $P$, Thomson B, Carling J, Huttner E, Ambrogio ED, Kilian A: An integrated DArT-SSR linkage map of durum wheat. Mol Breed 2008, 22:629-648.

15. Peleg Z, Saranga Y, Suprunova T, Ronin YW, Röder MS, Kilian A, Korol AB, Fahima T: High-density genetic map of durum wheat $\times$ wild emmer wheat based on SSR and DArT markers. Theor Appl Genet 2008, 117:103-115.

16. Francki MG, Walker E, Crawford AC, Broughton S, Ohm HW, Barclay I, Wilson RE, McLean R: Comparison of genetic and cytogenetic maps of hexaploid wheat (Triticum aestivum L.) using SSR and DArT markers. Mol Genet Genomics 2009, 281:181-191.

17. Wang YY, Sun XY, Zhao Y, Kong FM, Guo Y, Zhang GZ, Pu YY, Wu K, Li SS: Enrichment of a common wheat genetic map and QTL mapping for fatty acid content in grain. Plant Sci 2011, 181:65-75.

18. Huang BE, Cavanagh C, Rampling L, Kilian A, Geroge A: iDArTs: increasing the value of genomic resources at no cost. Mol Breed 2012, 30:927-938.

19. Cui F, Zhao CH, Ding AM, Li J, Wang L, Li XF, Bao YG, Li JM, Wang HG: Construction of an integrative linkage map and QTL mapping of grain yield-related traits using three related wheat RIL populations. Theor Appl Genet 2014, 127:659-675.

20. Habash DZ, Bernard S, Schondelmaier JS, Weyen J, Quarrie SA: The genetics of nitrogen use in hexaploid wheat: $\mathrm{N}$ utilisation, development and yield. Theor Appl Genet 2007, 114:403-419.

21. Laperche A, Brancourt-Hulmel M, Heumez E, Gardet O, Hanocq E, DevienneBarret FD, Gouis JL: Using genotype $\times$ nitrogen interaction variables to evaluate the QTL involved in wheat tolerance to nitrogen constraints. Theor App/ Genet 2007, 115:399-415.

22. Laperche A, Gouis JL, Hanocg E, Brancourt-Hulmel M: Modelling nitrogen stress with probe genotypes to assess genetic parameters and genetic determinism of winter wheat tolerance to nitrogen constraint. Ephytica 2008, 161:259-271.

23. Cui ZL, Zhang FS, Chen XP, Li F, Tong YP: Using in-season nitrogen management and wheat cultivars to improve nitrogen use efficiency. Soil Sci Soc Am J 2011, 75:1-8.

24. Wang RF, An DG, Hu CS, Li LH, Zhang YM, Jia YG, Tong YP: Relationship between nitrogen uptake and use efficiency of winter wheat grown in the North China Plain. Crop Pasture Sci 2011, 62:504-514.

25. Peng JH, Lapitan NLV: Characterization of EST-derived microsatellites in the wheat genome and development of Essr markers. Funct Integr Genomic 2005, 5:80-96.

26. Mullan DJ, Platteter A, Teakle NL, Appels R, Colmer TD, Anderson JM, Francki $M G$ : EST-derived SSR markers from defined regions of the wheat genome to identify Lophopyrum elongatum specific loci. Genome 2005, 48:811-822
27. Zhuang LF, Song LX, Feng YG, Qian BL, Xu HB, Pei ZY, Qi ZJ: Development and chromosome mapping of $81 \mathrm{New}$ wheat E-SSR markers and application for characterizing Rye chromosomes added in wheat. Acta Agron Sin 2008, 34(6):926-933.

28. Li LZ, Wang JJ, Guo Y, Jiang FS, Xu YF, Wang YY, Pan HT, Han GZ, Li RJ, Li SS: Development of SSR markers from ESTs of gramineous speciesand their chromosome location on wheat. Prog Nat Sci 2008, 18:1485-1490.

29. Yang XQ, Liu P, Han ZF, Ni ZF, Liu WQ, Sun QX: Comparative analysis of genetic diversity revealed by genomic-SSR, E-SSR and pedigree in wheat (Triticum asetivum L.). Acta Genet Sin 2005, 32(4):406-416.

30. Lu JF, Ren ZL, Gao LF, Jia JZ: Developing new SSR markers from EST of wheat. Acta Agron Sin 2005, 31(2):154-158.

31. Liu YN, He ZH, Appels R, Xia XC: Functional markers in wheat: current status and future prospects. Theor Appl Genet 2012, 125:1-10.

32. Hao YF, Liu AF, Wang YH, Feng DS, Gao JR, Li XF, Liu SB, Wang HG: Pm23: a new allele of Pm4 located on chromosome $2 \mathrm{AL}$ in wheat. Theor Appl Genet 2008, 117:1205-1212.

33. Singh NK, Shepherd KW, Cornish GB: A simplified SDS-PAGE procedure for separating LMW subunits of glutenin. J Cereal Sci 1991, 14:203-208.

34. Lander ES, Green P, Abrahamson J, Barlow A, Daly MJ, Lincoln SE, Newberg L: MAPMAKER: an interactive computer package for constructing primary genetic linkage maps of experimental and natural populations. Genomics 1987, 1:174-181.

35. Kosambi DD: The estimation of map distances from recombination values. Ann Eugen 1994, 12:172-175.

36. Voorips RE: Mapchart: software for the graphical presentation of linkage maps and QTLs. J Hered 2002, 93:77-78.

37. Sourdille P, Singh S, Cadalen T, Gina L, Brown-Guedira GL, Gay G, Qi LL, Gill BS, Dufour P, Murigneux A, Bernard M: Microsatellite-based deletion bin system for the establishment of genetic-physical map relationships in wheat (Triticum aestivum L.). Funct Integr Genomic 2004, 4:12-25.

38. Sourdille P, Cadalen T, Guyomarc'h H, Snape JW, Perretant MR, Charmet G, Boeuf C, Bernard S, Bernard M: An update of the Courtot $\times$ Chinese Spring intervarietal molecular marker linkage map for the QTL detection of agronomic traits in wheat. Theor App/ Genet 2003, 106:530-538.

39. Röder MS, Korzun V, Wendehake K, Tixier MH, Leroy P, Ganal MW: A microsatellite map of wheat. Genetics 1998, 149:2007-2023.

40. Song QJ, Shi JR, Singh S, Fickus EW, Costa JM, Lewis J, Gill BS, Ward R, Cregan PB: Development and mapping of microsatellite (SSR) markers in wheat. Theor Appl Genet 2005, 110:550-560.

41. Gadaleta A, Giancaspro A, Giove SL, Zacheo S, Mangini G, Simeone R, Signorile A, Blanco A: Genetic and physical mapping of new EST-derived SSRs on the A and B genome chromosomes of wheat. Theor Appl Genet 2009, 118:1015-1025.

42. Marone D, Laidò G, Gadaleta A, Colasuonno P, Ficco DBM, Giancaspro A, Giove S, Panio G, Russo MA, Vita PD, Cattivelli L, Papa R, Blanco A Mastrangelo AM: A high-density consensus map of $A$ and $B$ wheat genomes. Theor Appl Genet 2012, 106:1619-1638.

43. Somers DJ, Isaac $P$, Edwards K: A high-density microsatellite consensus map for bread wheat (Triticum aestivum L.). Theor Appl Genet 2004, 109:1105-1114.

44. Nachit MM, Elouafi I, Pagnotta MA, EI SA, Lacono E, Labhilili M, Asbati A, Azrak M, Hazzam H, Benscher D, Khairallah M, Ribaut J-M, Tanzarella OA, Porceddu E, Sorrells ME: Molecular linkage map for an intraspecific recombinant inbred population of durum wheat (Triticum turgidum $\mathrm{L}$. var. durum). Theor App/ Genet 2001, 102:177-186.

45. Lagudah ES, Appels R, Brown AHD, McNeil D: The molecular-genetic analysis of Triticum tauschii, the D-genome donor to hexaploid wheat. Genome 1991, 34:375-386.

46. Torada A, Koike M, Mochida K, Ogihara Y: SSR-based linkage map with new markers using an intraspecific population of common wheat. Theor Appl Genet 2006, 112:1042-1051.

47. Kantety RV, La Rota M, Matthews DE, Sorrells ME: Data mining for simple sequence repeats in expressed sequence tags from barley, maize, rice, sorghum and wheat. Plant Mol Biol 2002, 48:501-510.

48. Zhang KP, Zhao L, Tian JC, Chen GF, Jiang XL, Liu B: A genetic map constructed using a doubled haploid population derived from two elite Chinese common Wheat varieties. J Integr Plant Biol 2008, 50:941-950.

49. Blanco A, Bellomo MP, Cenci A, De Giovanni C, D'Ovidio R, lacono E, Laddomada B, Pagnotta MA, Porceddu E, Sciancalepore A, Simeone R, 
Tanzarella OA: A genetic linkage map of durum wheat. Theor App/ Genet 1998, 97:721-728.

50. Sears ER: The aneuploids of common wheat. Missouri Agric Exp Sta Res Bull 1954, 572:59.

51. Jha KK: The association of a gene for purple coleoptile with chromosome 7D of common wheat. Can J Genet Cytol 1964, 6:370-372.

52. Kuspira J, Unrau J: Determination of the number and dominance relationships of genes on substituted chromosomes in common wheat Triticum aestivum L. Can J Plant Sci 1958, 38:199-205.

53. Paillard S, Schnurbusch T, Winzeler M, Messmer M, Sourdille P, Abderhalden $O$, Keller B, Schachermayr G: An integrative genetic linkage map of winter wheat (Triticum aestivum L.). Theor Appl Genet 2003, 107:1235-1242.

54. Akhunov ED, Akhunova AR, Linkiewicz AM, Dubcovsky J, Hummel D, Lazo G, Chao S, Anderson OD, David J, Qi L, Echalier B, Gill BS, Miftahudin, Gustafson JP, La Rota M, Sorrells ME, Zhang D, Nguyen HT, Kalavacharla V, Hossain K, Kianian SF, Peng J, Lapitan NL, Wennerlind EJ, Nduati V, Anderson JA, Sidhu D, Gill KS, McGuire PE, Qualset CO, et al: Synteny perturbations between wheat homeologous chromosomes caused by locus duplications and deletions correlate with recombination rates. Proc Natl Acad Sci U S A 2003, 100:10836-10841.

55. Akhunov ED, Goodyear AW, Geng S, Qi LL, Echalier B, Gill BS, Miftahudin, Gustafson JP, Lazo G, Chao S, Anderson OD, Linkiewicz AM, Dubcovsky J, Rota ML, Sorrells ME, Zhang D, Nguyen HT, Kalavacharla V, Hossain K, Kianian SF, Peng J, Lapitan NLV, Gonzalez-Hernandez J, Anderson JA, Choi D-W, Close TJ, Dilbirligi M, Gill KS, Walker-Simmons MK, Steber C, et al: The organization and rate of evolution of wheat genomes are correlated with recombination rates along chromosome arms. Genome Res 2003, 13:753-763.

56. Qi LL, Echalier B, Chao S, Lazo GR, Butler GE, Anderson OD, Akhunov ED, Dvorak J, Linkiewicz AM, Ratnasiri A, Dubcovsky J, Bermudez-Kandianis CE, Greene RA, Kantety R, La Rota CM, Munkvold JD, Sorrells SF, Sorrells ME, Dilbirligi M, Sidhu D, Erayman M, Randhawa HS, Sandhu D, Bondareva SN, Gill KS, Mahmoud AA, Ma XF, Miftahudin, Gustafson JP, Conley EJ, et al: A chromosome bin map of 16,000 expressed sequence tag loci and distribution of genes among the three genomes of polyploidy wheat. Genetics 2004, 168:701-712.

57. Zhang L, Luo JT, Hao M, Zhang LQ, Yuan ZW, Yan ZH, Liu YX, Zhang B, Liu BL, Liu CJ, Zhang HG, Zheng YL, Liu DC: Genetic map of Triticum turgidum based on a hexaploid wheat population without genetic recombination for D genome. BMC Genet 2012, 13:69. doi:10.1186/1471-2156-13-69.

58. Lyttle TW: Segregation distorters. Annu Rev Genet 1991, 25:511-557.

59. Xu Y, Zhu L, Xiao J, Huang N, McCouch SR: Chromosomal regions associated with segregation distortion of molecular markers in $F_{2}$ backcross, doubled haploid, and recombinant inbred populations in rice (Oryza sativaL.). Mol Gen Genet 1997, 253:535-545.

60. Tanksley SD: Linkage relationships and chromosomal locations of enzyme-coding genes in pepper, Capsicum annum. Chromosoma 1984, 89:352-360.

61. Chu CG, Xu SS, Friesen TL, Faris JD: Whole genome mapping in a wheat doubled haploid population using SSRs and TRAPs and the identification of QTL for agronomic traits. Mol Breed 2008, 22:251-266.

62. Alheit KV, Reif JC, Maurer HP, Hahn V, Weissmann EA, Miedaner T, Würschum T: Detection of segregation distortion loci in triticale ( $x$ Triticosecale Wittmack) based on a high-density DArT marker consensus genetic linkage map. BMC Genomics 2011, 12:380

63. Suenaga $K$, Khairallah M, William HM, Hoisington DA: A new intervarietal linkage map and its application for quantitative trait locus analysis of "gigas" features in bread wheat. Genome 2005, 48:65-75.

doi:10.1186/1471-2156-15-57

Cite this article as: Cui et al: A novel genetic map of wheat: utility for mapping QTL for yield under different nitrogen treatments. BMC Genetics 2014 15:57.

\section{Submit your next manuscript to BioMed Central and take full advantage of:}

- Convenient online submission

- Thorough peer review

- No space constraints or color figure charges

- Immediate publication on acceptance

- Inclusion in PubMed, CAS, Scopus and Google Scholar

- Research which is freely available for redistribution

Submit your manuscript at www.biomedcentral.com/submit
C Biomed Central 